Any scientist who has had this experience will recognize at once what he means. To see such an "image" of the shape of a system unfolding before your inner eye is the rare and supreme reward of the investigator. Professor Pantin did well to try even hesitantly to show it to us as the real aim and end of our endeavours. He has not provided us with a complete theoretical account of the basis of science. But in this posthumous book, as in his life, he shows us something of how a scientist really works.

J. Z. YOUNG

\section{RESEARCH AND FARMING}

\section{Organisation and Administration of Agricultural Research \\ By I. Arnon. Pp. xii +342 . (Elsevier: Amsterdam,} London and New York, 1968.) $80 s$.

THE same general principles apply to agricultural research as to any other kind of research devoted to a science based industry. In this comprehensive and useful review, Dr Arnon has recognized the common features and has drawn extensively on the writings of other authors concerned with a diversity of industrial as well as agricultural research to illustrate and develop his own ideas. Unfortunately, because much of the world's agricultural production is based on peasant farming systems, it is not generally appreciated that scientific research has played an important part in increasing productivity. It is unlikely therefore that this book will be widely read other than by scientists and administrators concerned with agriculture. This is a pity because its critical commentary is applicable to much wider interests.

The opening chapter gives an account of the history and evolution of agricultural research together with a description of the present day organization in a number of countries which include examples of both advanced and developing systems of agriculture. The author's own ideas on the ideal organization begin to emerge in this chapter. He makes it clear that he favours an arrangement in which the "Ministry of Agriculture" holds responsibility for policy making and for telling the scientists what they are to do although, of course, not how they are to do it. He quotes the FAO conference of 1965 which suggested a "National Research Institute" enjoying a "semi-autonomous" status within the framework of a ministry of agriculture. He realizes, however, that scientists resent being administered by permanent officials who are not technically qualified. Most of them would prefer that their research should be directed by other scientists within a "Research Council" type of organization, but Arnon argues that there is a serious risk in such a system that research will be divorced from "agricultural realities".

Chapters two and three are concerned with international cooperation and with a consideration of the role and character of agricultural research. The latter is disappointing and confusing because the author, while acknowledging the ambiguity which attaches to the definition of different kinds of research, then attempts to define precisely his own and other people's terms, including such incomprohensiblo ones as "programmatic fundamental research" and "establishment fundamental research".

By contrast, the chapters on research planning and the infra-structure of a research organization give an excellent account of planning at all levels from the formulation of national policy for research down to a consideration of the priority attaching to individual research projects. It is here that the wisdom and authority of the author, derived from long experience in many roles in a research organization, show through clearly. Arnon recognizes the need for a balance between fundamental, long-term and applied, short-term research to maintain the organization in a dynamic and productive condition. He favours the inter- disciplinary rather than the crop-oriented research institute, but appreciates that funds can most logically be allocated on the basis of the value of the particular sector of the industry which the research is intended to serve.

Theories of management are discussed and a most perceptive analysis is given of the problems facing the scientist turned administrator. Arnon accepts that research and development require enlightened management just as much as the production side of industry. He understands, too, that training in management must be provided for potential research leaders.

In the later chapters, critical consideration is given to the "team" approach to research and to the concept of the research "project"; much of this is familiar but still worthwhile to complete the review. Finally, there is an important chapter on the translation of research findings into farming practice. Although Arnon suggests that the extension (advisory) worker is the logical agent to explain the results of research to the farmer, he argues convincingly that the research organization should assume responsibility for developing a new idea from its inception through to the field experiments that will establish its applicability to farming practice. There will be many who will agree with this view.

This is an interesting and a useful book. Its comprehensiveness is a valuable feature, but it makes for exhausting reading and the major criticism must be that Arnon is so determined not to omit any relevant reference to other people's views that it is not always easy to discern his own.

D. Rudd Jones

\section{SCIENCE IN HISTORY}

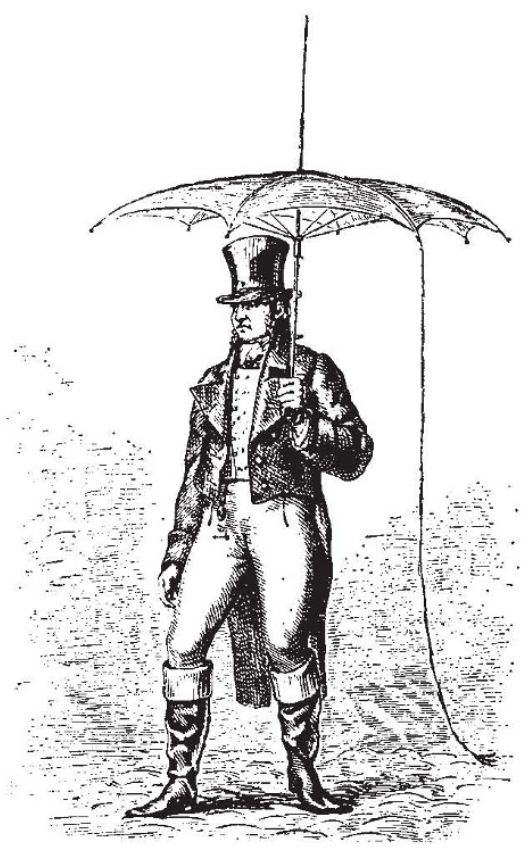

Benjamin Franklin's discovery of the value of the lightning conductor in the mid-nineteenth century led to many kinds of extravagances. Jacques Barbeu-Dubourg, a member of the Académie des Sciences, even went so far as to invent a portable lightning conductor built into an umbrella. This illustration, taken from Les Merveilles de Science, by Louis Figuier (Paris, c. 1870), is one of the 398 pictures in the new edition of J. D. Bernal's classic book, Science in History. The first edition of this book, published by C. A. Watts in 1954, had very few illustrations. Penguin Books and Watts have now brought out a special illustrated version of the third edition of 1965 , in boxed sets of four volumes. (Penguin: Harmondsworth, Middlesex; Watts: London, February 1969. Pelican $80 \mathrm{~s}$; Watts hardback 200s.) 